\title{
Monomer-dimer Equilibrium of Mycobacterium tuberculosis Alanine Racemase Depends on Buffer Conditions
}

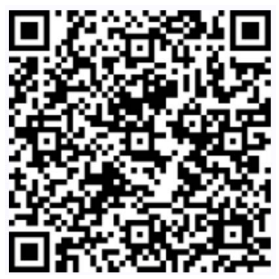

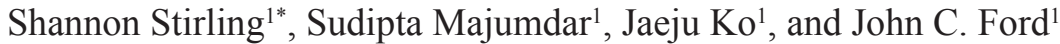

Mycobacterium tuberculosis causes epidemic levels of tuberculosis each year and more strains of the disease are becoming resistant to the medications used to treat it. Alanine racemase is a convenient target for new drug candidates for tuberculosis as this enzyme is not found in human cells and in M. tuberculosis is only active when in the dimer form. To elucidate the dimerization process, the equilibrium association constants for monomer-dimer equilibrium were determined using high-performance size-exclusion liquid chromatography in a variety of mobile phases. Alanine racemase appeared to be a high-equilibrium association constant dimer in all mobile phases. The degree of dimerization was sensitive to $\mathrm{pH}$ and solution composition; phosphate decreases the fraction of alanine racemase dimers. These findings will be useful in designing new antibiotics that target alanine racemases.

\section{INTRODUCTION}

Mycobacterium tuberculosis is the species of bacteria responsible for the world-wide epidemic of tuberculosis (TB). A fourth of the world's population is currently infected and worldwide, there were 1.7 million TB-related deaths in 2016. The World Health Organization has ranked TB as the second-most common infection and the third leading cause of death from a single infectious agent (World Health Organization, 1996). Several antibiotics are currently on the market to treat $\mathrm{TB}$, but multiple strains of the bacterium are becoming resistant to treatment. This problem has become so prevalent that two new classifications of TB have been created, 'Multidrug-resistant' and 'Extensively Drug-resistant'. As resistance continues to increase, the need for new drugs becomes increasingly important. Alanine racemase (ALR), an enzyme essential for the formation of the bacterium's cell wall, is a viable target for the treatment of TB (Anthony et al., 2011; Azam and Jayaram, 2016).

Alanine racemase is a pyridoxial-5-phosphate (PLP)-dependent protein that converts L-alanine to D-alanine, a necessary component of the cell wall of both Gram-positive and Gram-negative bacteria. The enzyme is found in most bacterial species and there are no known homologs in humans. This key fact has encouraged an array of studies into potential drug candidates targeting ALR

\footnotetext{
${ }^{1}$ Department of Chemistry, Indiana University of Pennsylvania, Indiana, PA 15705
}

*To whom correspondence should be addressed: shansnow07@gmail.com

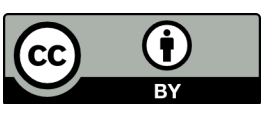

Except where otherwise noted, this work is licensed under https://creativecommons.org/licenses/by/4.0

doi:10.22186/jyi.36.4.50-54
(Azam and Jayaram, 2016).

Several known inhibitors of $M$. tuberculosis ALR (Mt-ALR) work by binding to the substrate-binding site proximal to the bound PLP (Anthony et al., 2011). Among known inhibitors of Mt-ALR, only D-cycloserine, a substrate analog, is used medically to treat TB. However, D-cycloserine carries substantial side effects because it inactivates ALR by binding to the enzyme-bound PLP and PLP-dependent enzymes are essential for many eukaryotic systems. In humans, PLP is important for proper neural functioning. Disruption of PLP binding has led to reports of dizziness, coma, depression, and other neurological and psychotic disorders in D-cycloserine users (Walsh, 2003).

Anthony et al. (2011) have identified new classes of ALR inhibitors by high-throughput screening of 53,000 compounds. Upon analyzing synthetic compound libraries, 472 hits were found, with only 25 strong hits. All of the hits came from the synthetic compound libraries analyzed; their strategy was to select inhibitors that are not substrate analogs. Similarly, to avoid selecting the inhibitors that are substrate analogs, some authors have suggested the inclusion of conserved residues at the entrance to the catalytic pocket of $M t$-ALR as additional targets in structure-aided drug design (LeMagueres et al., 2005). Others have suggested designing inhibitors that bind to the dimer interface to block dimerization (Azam and Jayaram, 2016). One of the goals of the current study was to understand the dimerization of ALRs and thus aid in the design of inhibitors, which could serve as drugs, that work by interfering with the dimerization of $M t$-ALR.

ALR has long been recognized as a potential target for drug design (Silverman, 1988). While some species show monomeric ALR, most ALR exhibit dimeric forms (Ju et al., 2011). Yokoigawa et al. (2003) first reported a dynamic monomer-dimer equilibrium in the case of ALR from 4 Shigella species. Ju et al. (2005) 
showed this to be the case for ALR from Pseudomonas fluorescens as well. More recently, Ju et al. (2011) showed the same for the catabolic or biosynthetic ALRs from five different, Gram-negative bacteria. It has been shown that the ALR from the thermophilic Thermoanaerobacter tengcongensis MB4 has a molecular mass of $76 \mathrm{kDa}$ in solution by size-exclusion chromatography (SEC) while the calculated monomer weight was $46.6 \mathrm{kDa}$; however, dynamic light scattering gave a hydrodynamic radius which "corresponded to a molecular mass of $110 \mathrm{kDa}$," (Xue et al., 2013). Asojo et al. (2014) showed that ALR from a Clostridium difficile strain exists in solution with an apparent molecular mass of $81 \mathrm{kDa}$, while the calculated dimer would be $87 \mathrm{kDa}$. These latter two studies (Asojo et al., 2014; Xue et al., 2013) are also consistent with a monomerdimer equilibrium which favors the dimer.

Pseudomonas fluoresens, T. tengcongensis, and C. difficile are all Gram-negative bacteria. The monomer-dimer equilibrium of ALR appears to also be found in Gram-positive bacteria, as some studies have found a solution molecular mass of $73 \mathrm{kDa}$ by dynamic light scattering for the ALR of the Gram-positive organism Staphylococcus aureus, which has a calculated monomer weight of $42.8 \mathrm{kDa}$ (Scaletti et al., 2012).

Originally, ALRs were classified as either being monomeric enzymes or homodimeric enzymes regardless of species (Yokoigawa et al., 2003). However, it has been proposed that ALRs should be reclassified as either enzymes with low association constants or high association constants for dimerization (Ju et al., 2011). The $\mathrm{Ju}$ et al. (2011) study reports the association constants for dimerization of seven ALRs (3 biosynthetic and 4 catabolic). The study also found that $\mathrm{V}_{\max }$ values exhibit a positive correlation with the monomer-dimer association constants. While the active form of $M t$-ALR is believed to be a dimer (LeMagueres et al., 2005), MtALR was not included in the Ju et al. study. In this paper, we report the association constant for biosynthetic ALR from M. tuberculosis (Mt-ALR) over a range of $\mathrm{pH}$ values and ionic strengths using high-performance size-exclusion chromatography (SEC).

\section{MATERIALS AND METHODS}

\section{Materials}

The cloning of the $M t$-ALR gene as well as the expression and purification of Mt-ALR is (Cook et al., 2018). The sources of the size exclusion chromatography standards are listed in Table 1. All mobile phases were prepared using reagent grade or higher standard components and Type I water.

\section{Instrumentation}

All chromatographic experiments were performed on a Prominence HPLC comprised of a Model DGU-20A5 degasser, a Model LC-20AT low pressure quaternary pump, a Model SIL-20AC HT autosampler, a Model CBM-20A communication bus module, and a Model SPD-M20A diode array detector (Shimadzu Scientific Instruments, Columbia, MD). Retention times were taken at the peak maxima, as reported by LCsolutions software (Shimadzu). The injection volume for the ALR samples was $10 \mu \mathrm{L}$. The injection volume of the calibration proteins varied from $1 \mu \mathrm{L}$ to $5 \mu \mathrm{L}$, depending on the concentration of the protein.

The experiments were performed on an ENrich SEC 650 column (10x300mm, 24 mL, Bio-Rad Laboratories, Inc., Hercules, CA). The column manufacturer states that the column is stable over the $\mathrm{pH}$ range 2-12 (BioRad, n.d.). The column was between 22 and $24^{\circ} \mathrm{C}$ for all experiments.

\section{Mobile phase preparation}

All mobile phases were prepared so that the buffering component was at $50 \mathrm{mM}$ and the $\mathrm{NaCl}$ concentration was $100 \mathrm{mM}$. In the case of mixed buffers, the total concentration of the buffering components was $50 \mathrm{mM}$. The buffering component was weighed and added to Type 1 water. The appropriate volume of a stock $1 \mathrm{M}$ $\mathrm{NaCl}$ solution was added to this solution and the solution brought to final volume. The $\mathrm{pH}$ of the mobile phase was adjusted with $\mathrm{HCl}$ and $\mathrm{NaOH}$ and it was filtered through a 0.45 -micron hydrophilic polypropylene filter before use.

\section{Calibration of the size-exclusion column}

The column was calibrated in $\mathrm{pH} 6.0$ and 7.0 phosphate mobile phases and in a pH 8.0 mixture of carbonate, bicine, and borate. All mobile phases contained $100 \mathrm{mM} \mathrm{NaCl}$. Each of the nine molecular mass standards (Table 1) was run at a flow rate of $0.5 \mathrm{~mL} /$ min at ambient temperature. Retention volume was determined from the retention times and the flow rate of the HPLC. The standards were run 6 times during the course of the experiments using a $\mathrm{pH} 7.0$ phosphate mobile phase; the retention times were essentially constant, with deviations not greater than $0.05 \mathrm{~mL}$ in retention volume.

Size-exclusion chromatographic analysis of $\mathbf{M t}$-ALR

The ENrich SEC 650 column was equilibrated with $30-90 \mathrm{~mL}$

Table 1. Size-exclusion standards used for molecular mass determinations.

\begin{tabular}{|c|c|c|}
\hline Protein & $\begin{array}{l}\text { Molecular } \\
\text { Mass (kDa) }\end{array}$ & Source \\
\hline Blue Dextran & 2000 & $\begin{array}{c}\text { Gel Filtration Marker Kit for Pro- } \\
\text { tein Molecular Weights 29000- } \\
700000 \mathrm{Da} \text {, Sigma Aldrich }\end{array}$ \\
\hline Thyroglobulin & 669 & (See source for Blue Dextran) \\
\hline Apoferritin & 443 & (See source for Blue Dextran) \\
\hline Beta-Amylase & 200 & (See source for Blue Dextran) \\
\hline Transferrin & 80 & $\begin{array}{l}\text { SigmaProt Intact Protein LC-MS } \\
\text { standard, Sigma Aldrich }\end{array}$ \\
\hline $\begin{array}{l}\text { Bovine Serum } \\
\text { Albumin }\end{array}$ & 64 & (See source for Blue Dextran) \\
\hline Ovalbumin & 44 & $\begin{array}{l}\text { Sigma chemical Co. Lot } \\
\quad \# 14 \mathrm{H} 7035\end{array}$ \\
\hline $\begin{array}{l}\text { Carbonic } \\
\text { anhydrase }\end{array}$ & 29 & (See source for Blue Dextran) \\
\hline Ribonuclease & 13.7 & $\begin{array}{c}\text { Protein standard mix } 15-600 \mathrm{kDa} \text {, } \\
\text { Sigma Aldrich }\end{array}$ \\
\hline
\end{tabular}


of mobile phase prior to the running of any Mt-ALR or standard. Equilibration was assumed complete when a steady baseline was obtained. Once equilibrated, a $10 \mu \mathrm{L}$ injection of $M t$-ALR was performed by the auto-sampler. Each Mt-ALR sample was run for one hour at ambient temperature. The apparent molecular mass of $M t$-ALR was determined by comparison of the elution time to the pH 7.0 calibration curve.

The precision of the molecular mass determination was estimated by calculating the overall relative standard deviation (RSD) of six sets of replicate measurements (totaling 24 individual retention measurements). The precision was approximately $1 \% \mathrm{RSD}$, or about $0.6 \mathrm{kDa}$.

Martin (1949) first showed that the retention factor $R$ of a species undergoing a reaction is given by the sum of the retention factors of each form weighted by the mole fraction of that form,

$$
R=\sum_{i} f_{i} R_{i}
$$

where $f_{i}$ is the mole fraction of the $i^{\text {th }}$ form and $R_{i}$ is the retention factor of the $i^{\text {th }}$ form. Therefore, if only two forms (monomer and dimer) exist, the apparent molecular mass is

$$
M_{\text {exp }}=f_{1} M_{1}+f_{2} M_{2}
$$

where $M_{\text {exp }}$ is the experimentally observed apparent molecular mass, $M_{1}$ is the molecular mass of the monomer, and $M_{2}$ is the molecular mass of the dimer; $f_{1}$ and $f_{2}$ are the mole fractions present as monomer and dimer, respectively. Thus, the value of the apparent molecular mass depends on the association constant for the dimerization as well as the kinetics of the reaction (Yu et al., 2006). A monomer in rapid equilibrium with its dimer will elute from a SEC column with an apparent molecular mass that is between the molecular masses of the monomer and the dimer.

Consider a monomer $(A)$ in equilibrium with its $\operatorname{dimer}\left(A_{2}\right)$,

$$
2 \mathrm{~A} \rightleftharpoons \mathrm{A}_{2}
$$

The equilibrium constant $K_{\text {dimer }}$ is:

$$
K_{\text {dimer }}=\left[A_{2}\right] /[A]^{2}
$$

Where $[\mathrm{A}]$ is the molar concentration of the monomer and $\left[\mathrm{A}_{2}\right]$ is the molar concentration of the dimer. We also know that:

$$
f_{1}+f_{2}=1
$$

Then equations 3,4 , and 5 can be combined to give:

$$
K_{\text {dimer }}=\frac{\frac{f_{2}}{\left(1+f_{2}\right)}\left[M_{0}\right]}{\left(\frac{f_{1}}{1+f_{2}}\right)^{2}\left[M_{0}\right]^{2}}
$$

where $\left[M_{\mathrm{o}}\right]$ is the total, formal concentration of the enzyme.
From equations 2 and 6 , we get:

$$
K_{\text {dimer }}=\frac{\left(M_{\text {exp }}-M_{l}\right) \mathrm{M}_{\exp }}{\left(2 M_{1}-M_{e x p}\right)^{2}\left[M_{0}\right]}
$$

In which only the experimentally obtained $M_{\text {exp }}$ and the total, formal concentration of the enzyme $\left[M_{\mathrm{o}}\right]$ are needed to evaluate the association constant $K_{\text {dimer }}$

The concentration of a solute changes as it elutes through a chromatographic column. Assuming Gaussian behavior, the ratio of the solute's concentration on the column, $c$, to the concentration of the injected solute, $C_{\mathrm{inj}}$, is given by:

$$
\frac{C}{C_{i n j}}=\frac{V_{i n j} \sqrt{N}}{V_{R} \sqrt{2 \pi}}
$$

where $V_{\text {inj }}$ and $V_{\mathrm{R}}$ are the injection and retention volumes, respectively, and $N$ is the column efficiency (Snyder and Kirkland, 1979). Since $V_{\mathrm{R}}$ increases linearly as the solute moves down the column, but $\mathrm{N}$ increases as a square root, the first $10 \%$ of the column is responsible for the majority of the dilution. For Mt-ALR, the concentration varied from 19.4 to $0.3 \mu \mathrm{M}$ within the first $10 \%$ of migration, but only from 0.33 to $0.11 \mu \mathrm{M}$ during the remaining $90 \%$, with the calculated average being $0.16 \mu \mathrm{M}$. Substituting this

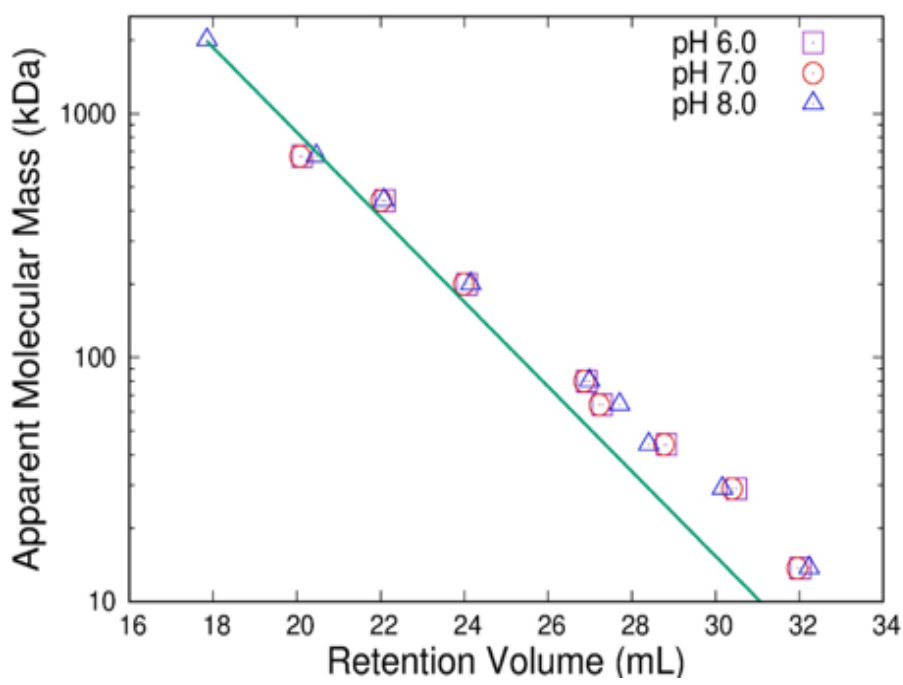

Figure 1. Relationship between the molecular mass of protein standards and the retention volume, used as the calibration curve for determining the apparent molecular mass of M. tuberculosis alanine racemase. The retention volumes remained essentially constant over the $\mathrm{pH}$ values of 6.0, 7.0, and 8.0. The line of best fit was constructed using all three $\mathrm{pH}$ values. The apparent larger deviation at lower molecular mass is due to the logarithmic relationship, not greater errors in that range. Measurements performed on a Bio-Rad ENrich SEC 650 column at ambient temperature and a flow rate of $0.50 \mathrm{~mL} / \mathrm{min}$. The protein standard $(2000$ $\mathrm{kDa}$ ) was tested at only $\mathrm{pH} 8$ for stability reasons. 
Table 2. Apparent molecular mass of M. tuberculosis alanine racemase as determined by size-exclusion chromatography. Red indicates retention times in buffers without phosphate. ANOVA comparing the retention in buffers with phosphate to the retention in buffers without phosphate shows a statistically significant difference $(p=0.0039, d f=19)$.

\begin{tabular}{|c|c|c|c|c|}
\hline $\begin{array}{c}\text { Mobile Phase } \\
\text { (all with } 100 \mathrm{mM} \\
\mathrm{NaCl} \text { ) }\end{array}$ & $\begin{array}{l}\text { Total Con- } \\
\text { centration } \\
(\mathrm{mM})\end{array}$ & pH & $\begin{array}{c}\text { Apparent } \\
\text { Molecular } \\
\text { Mass (kDa)* }\end{array}$ & $\begin{array}{l}\text { Frac- } \\
\text { tion as } \\
\text { Dimer }\end{array}$ \\
\hline Acetate & 50 & 5.00 & 64.7 & 0.578 \\
\hline Phosphate & 50 & 6.00 & 68.3 & 0.667 \\
\hline Phosphate & 50 & 7.00 & 66.1 & 0.613 \\
\hline MOPS & 50 & 7.00 & 68.6 & 0.672 \\
\hline Phosphate + glycine & 50 & 7.00 & 63.4 & 0.546 \\
\hline Phosphate & 10 & 8.00 & $62.4,61.8^{* *}$ & $\begin{array}{l}0.521 \\
0.508^{*}\end{array}$ \\
\hline Phosphate & 10 & 8.00 & 74 & 0.806 \\
\hline Tris & 50 & 8.00 & 70.9 & 0.73 \\
\hline Bicine & 50 & 8.00 & 75.5 & 0.841 \\
\hline Phosphate + glycine & 50 & 8.00 & $63.1,62.0 * *$ & $\begin{array}{c}0.540 \\
0.513 * *\end{array}$ \\
\hline $\begin{array}{l}\text { Bicine }+ \text { borate }+ \\
\text { carbonate }\end{array}$ & 50 & 8.00 & 76.6 & 0.87 \\
\hline Glycine + phosphate & 50 & 8.50 & 62.1 & 0.515 \\
\hline Glycine $+\mathrm{NaOH}$ & 50 & 9.00 & 76.1 & 0.856 \\
\hline Glycine + phosphate & 50 & 9.00 & 61.8 & 0.507 \\
\hline Glycine + phosphate & 50 & 9.50 & 60.8 & 0.482 \\
\hline $\begin{array}{l}\text { Bicarbonate }+ \\
\text { carbonate }\end{array}$ & 50 & 9.57 & 66 & 0.611 \\
\hline $\begin{array}{l}\text { Bicarbonate }+ \\
\text { carbonate }\end{array}$ & 50 & 9.93 & 66.5 & 0.623 \\
\hline Glycine $+\mathrm{NaOH}$ & 50 & 10.00 & 71 & 0.733 \\
\hline $\begin{array}{c}\text { Bicarbonate }+ \\
\text { carbonate }\end{array}$ & 50 & 10.36 & 66.4 & 0.619 \\
\hline
\end{tabular}

*Each apparent molecular mass was obtained by averaging the values obtained for retention volume measurements

**These represent independent experiments and give an estimate of the experimental error.

value for $\left[M_{0}\right]$ in equation 7 , shown above, allows the determination of $K_{\text {dimer }}$.

\section{RESULTS}

\section{Retention volumes of standards}

The column manufacturer states that the column is stable over the $\mathrm{pH}$ range 2-12 (BioRad, n.d.) The retention volumes of the nine molecular mass standards at $\mathrm{pH}$ 6.0, 7.0 and 8.0 are presented in Figure 1, and were used as the size-exclusion chromatography (SEC) calibration curve. The apparent larger deviation at lower molecular mass is due to the logarithmic relationship, not greater errors in that range. Consistent with the manufacturer's specifi-

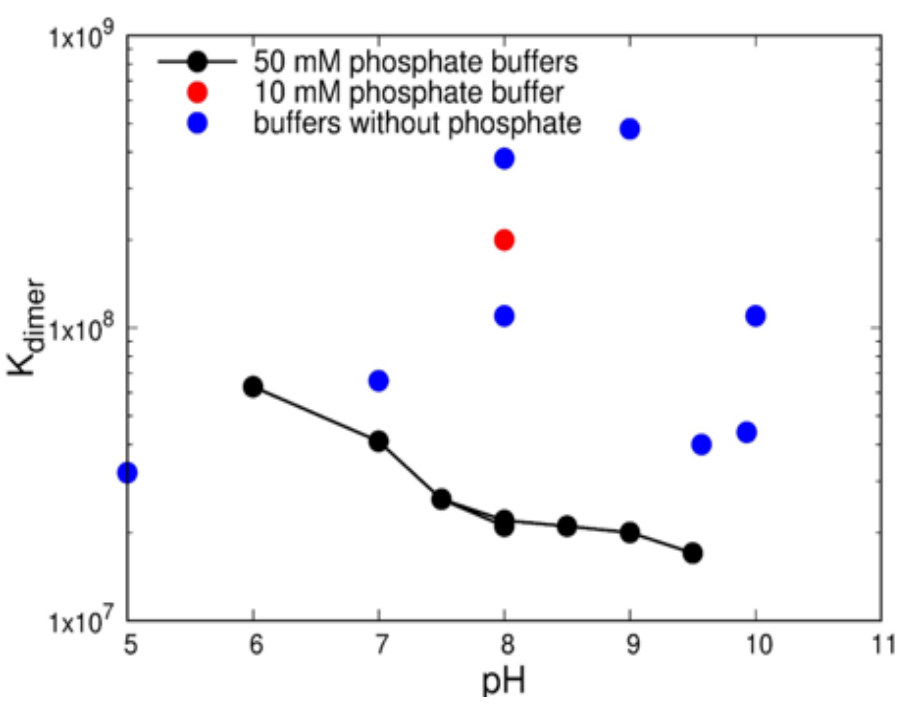

Figure 2. The equilibrium constant for dimerization $\left(K_{\text {dimer }}\right)$ of $M . t u$ berculosis alanine racemase as a function of $\mathrm{pH}$ and buffer conditions, determined using size exclusion chromatography. All buffers had 50 $\mathrm{mM}$ total buffering agent and $100 \mathrm{mM} \mathrm{NaCl} . K_{\text {dimer }}$ was calculated from the apparent molecular mass as described in the text. Buffers without phosphate showed greater dimerization than ones with phosphate.

cations, the retention volumes were essentially invariant over the $\mathrm{pH}$ 6.0-8.0 range tested. Reliable size standards over the entire $\mathrm{pH}$ 6.0-11.0 range were not available to us so it is conceivable that the retention characteristics of the column changed at $\mathrm{pH}$ levels above 8.0 , but unlikely as the column is specified to be stable up to $\mathrm{pH} 12.0$.

Apparent molecular mass and extent of dimerization of Mt-ALR

The apparent molecular mass of Mt-ALR at various $\mathrm{pH}$ and buffer systems was determined from the SEC calibration curve. These values are shown in Table 2. The anticipated molecular mass of ALR dimer is about $82 \mathrm{kDa}$. Thus, $M t$-ALR was neither completely dimer nor completely monomer in any of the tested systems.

The apparent molecular masses in Table 2 show no direct de-pendence on $\mathrm{pH}$ and appear quite scattered considering the preci-sion obtained between completely independent trials. The scatter is particularly evident at $\mathrm{pH} 8.0$, where six different buffer systems were used, and the apparent molecular masses ranged from 62.0 to $76.6 \mathrm{kDa}$.

If, however, one considers only those buffers without phos-phate, indicated in Table 2 in red, the apparent molecular masses at $\mathrm{pH} 8.0$ range from 70.9 to $76.6 \mathrm{kDa}$ for the 3 buffer systems. Restricting attention to the buffers without phosphate, over the $\mathrm{pH}$ range 5.0 to 10.4 , the apparent molecular mass starts at approxi-mately $64.7 \mathrm{kDa}$, increases to a maximum of $76.6 \mathrm{kDa}$ at $\mathrm{pH} 8.0$ and then decreases to approximately 66.4 $\mathrm{kDa}$ at $\mathrm{pH}$ 10.4. Gener-ally, lower apparent molecular masses were observed in the pres-ence of phosphate in buffers and higher apparent molecular masses were observed in the absence of phosphate. 
Also shown in Table 2 are the calculated fraction of the $M t$ ALR present as the dimer as shown in equation 7 above. An ANOVA of the values in the buffers without phosphate to those in the buffers with phosphate shows that the difference is statistically significant $(p=0.0039, d f=19)$. Thus, the presence of phosphate in the buffer reduced the extent of dimerization.

When the phosphate concentration is reduced from $50 \mathrm{mM}$ to $10 \mathrm{mM}$ at $\mathrm{pH} 8.0$, the apparent molecular mass of $M t$-ALR increased from approximately $62 \mathrm{kDa}$ to $74 \mathrm{kDa}$, essentially the same as that in the buffers without phosphate (Table 2).

\section{Determination of the association equilibrium constant}

The $K_{\text {dimer }}$ value was calculated following the procedure described above. Figure 2 shows the values obtained. For buffers containing phosphate, the smallest value was $1.7 \times 10^{7} \mathrm{M}^{-1}$, found in $\mathrm{pH} 9.5$, $25 \mathrm{mM}$ phosphate and $25 \mathrm{mM}$ glycine. The largest value was 2.4 $\mathrm{x} 10^{8} \mathrm{M}^{-1}$, found in $\mathrm{pH} 8.0,10 \mathrm{mM}$ phosphate. For buffers without phosphate, the smallest value was $3.2 \times 10^{7} \mathrm{M}^{-1}$ found in $\mathrm{pH}$ 5.0, $50 \mathrm{mM}$ acetate, while the largest value was $6.0 \times 10^{8} \mathrm{M}^{-1}$, found in $\mathrm{pH}$ 8.0, $16.7 \mathrm{mM}$ bicine, $16.7 \mathrm{mM}$ borate, and $16.7 \mathrm{mM}$ carbonate.

\section{DISCUSSION}

This study investigated the solution behavior of $M t$-ALR. Size-exclusion chromatography (SEC) revealed apparent molecular mass consistent with a monomer-dimer equilibrium over the $\mathrm{pH}$ range from 6.0 to 10.4. Furthermore, the position of the equilibrium was sensitive to the solution composition.

For $M t$-ALR, $K_{\text {dimer }}$ varied from $1.7 \times 10^{7}$ to $6.0 \times 10^{8} \mathrm{M}^{-1}$. In their examination of seven ALRs from Gram-negative bacteria, $\mathrm{Ju}$ et al. (2011) found values of $1.3 \times 10^{5} \mathrm{M}^{-1}$ to $1.6 \times 10^{6} \mathrm{M}^{-1}$, that is, two orders of magnitude lower. Their determinations were performed by sedimentation equilibrium measurements, with concentrations of approximately 5 to $10 \mu \mathrm{M}$, while the measurements here were performed approximately two orders of magnitude lower concentration. We note that their measurements were all at $\mathrm{pH}$ 7.0, with EDTA and PLP in solution, and the range represents ALRs from different species.

We studied $M t$-ALR in a variety of buffer systems covering a wide range of $\mathrm{pH}$. Many previous studies have used a phosphate buffer system to test of their ALR species (Ju et al., 2011; Yokoigawa et al., 2003). Our study found that phosphate has an interfering effect on ALR dimerization. We observed lower apparent molecular masses and lower equilibrium association constants in buffer systems containing $50 \mathrm{mM}$ phosphate. These results support the idea that phosphate inhibited the dimerization of ALR. This finding is important when designing inhibitors for $M t$-ALR and ALRs from other species, as a different buffer system could change a formally low-equilibrium association constant ALR species to high-equilibrium association constant species by the removal of phosphate in testing. When ALR inhibitors are tested, it should be remembered that phosphate also inhibits the dimerization of $M t$-ALR.

\section{ACKNOWLEDGMENTS}

This material is based upon work supported by the National Science Foundation under Grant No. CHE-0959229. We are also grateful to PA State System of Higher Education for the FPDC grant.

\section{REFERENCES}

Anthony KG, Strych U, Yeung KR, Shoen CS, Perez O, Krause KL, Cynamon, MH, Aristoff PA, Koski RA. (2011). New Classes of Alanine Racemase Inhibitors Identified by High-Throughput Screening Show Antimicrobial Activity against Mycobacterium tuberculosis. PLoS ONE, 6(5), 9.

Asojo OA, Nelson SK, Mootien S, Lee Y, Rezende WC, Hyman DA, Matsumoto MM, Reiling S, Kelleher A, Ledizet M, Koski RA, Anthony KG. (2014). Structural and biochemical analyses of alanine racemase from the multidrugresistant Clostridium difficile strain 630. Acta Crystallographica Section D, 70(7), 1922-1933. doi: doi:10.1107/S1399004714009419

Azam MA and Jayaram U. (2016). Inhibitors of alanine racemase enzyme: a review. Journal of Enzyme Inhibition and Medicinal Chemistry, 31(4), $517-$ 526. doi: 10.3109/14756366.2015.1050010

BioRad Laboratories. (n.d.) ENrich SEC 70 ENrich SEC 650 High-Resolution Size Exclusion Columns: Instruction Manual. Hercules, CA:Author.

Cook R, Barnhart R, Majumdar S. (2018). Effect of $\mathrm{pH}$ on the kinetics of alanine racemase from Mycobacterium tuberculosis. Journal of Young Investigators, $3(1), 4$.

Ju J, Xu S, Furukawa Y, Zhang Y, Misono H, Minamino T, Namba K, Zhao B, Ohnishi K. (2011). Correlation between catalytic activity and monomer-dimer equilibrium of bacterial alanine racemases. The Journal of Biochemistry, 149(1), 83-89. doi: 10.1093/jb/mvq120

Ju J, Yokoigawa K, Misono H, Ohnishi K. (2005). Cloning of alanine racemase genes from Pseudomonas fluorescens strains and oligomerization states of gene products expressed in Escherichia coli. Journal of Bioscience and Bioengineering, 100(4), 409-417. doi: 10.1263/jbb.100.409

LeMagueres P, Im H, Ebalunode J, Strych U, Benedik MJ, Briggs JM, Kohn H, Krause KL. (2005). The $1.9 \AA$ Crystal Structure of Alanine Racemase from Mycobacterium tuberculosis Contains a Conserved Entryway into the Active Site. Biochemistry, 44(5), 1471-1481. doi: 10.1021/bi0486583

Martin APJ. (1949). Some Theoretical Aspects of Partition Chromatography. Biochemical Society symposium, 3, 17.

Scaletti ER, Luckner SR, Krause KL. (2012). Structural features and kinetic characterization of alanine racemase from Staphylococcus aureus (Mu50). Acta Crystallographica Section D, 68(1), 82-92. doi: 10.1107/S0907444911050682

Shimadzu. LCsolutions (Version 1.25). Shimadzu Scientific Instruments, Colombia, MD: Shimadzu Scientific Instruments. Retrieved from https://www.ssi. shimadzu.com/products/informatics/class-agent-ver-2/specification.html

Silverman RB. (1988). The Potential Use of Mechanism-Based Enzyme Inactivators in Medicine. Journal of Enzyme Inhibition, 2(2), 73-90. doi: $10.3109 / 14756368809040714$

Snyder LR and Kirkland JJ. (1979). Introduction to Modern Liquid Chromatography (I. John Wiley \& Sons Ed. Second ed.).

Walsh C. (2003). Antibiotics: actions, origins, resistance. Washington: American Society for Microbiology (ASM).

World health report (1996). [Press release]. Retrieved from https://www.who.int/ whr/1996/media_centre/press_release/en/

Xue Z, Hu Y, Xu S, Ohnishi K, Mă Y, Ju J, Zhao B. (2013). Characterization and preliminary mutation analysis of a thermostable alanine racemase from Thermoanaerobacter tengcongensis MB4. Extremophiles, 17(4), 611-621. doi: 10.1007/s00792-013-0545-5

Yokoigawa K, Okubo Y, Soda K. (2003). Subunit interaction of monomeric alanine racemases from four Shigella species in catalytic reaction. FEMS Microbiology Letters, 221(2), 263-267. doi: 10.1016/S0378-1097(03)00216-7

Yu C-M, Mun S, Wang N-HL. (2006). Theoretical analysis of the effects of reversible dimerization in size exclusion chromatography. Journal of Chromatography A, 1132(1), 99-108. doi: https://doi.org/10.1016/j.chroma.2006.07.017 